\title{
Electron Transport and Oxidative Phosphorylation in the Blue-green Alga Anabaena variabilis
}

\author{
By C. K. LEACH AND N. G. CARR \\ Department of Biochemistry, The University of Liverpool, \\ P.O. Box 147, Liverpool, L69 $3 B X$ \\ (Accepted for publication 14 September 1970)
}

\begin{abstract}
SUMMARY
The respiratory electron transport system involved in NADPH $(2 \cdot 0$ nmoles/ $\mathrm{min} . / \mathrm{mg}$.) and NADH ( $10 \mathrm{nmoles} / \mathrm{min} . / \mathrm{mg}$.) oxidation in the dark that was operative in extracts of light-grown Anabaena variabilis has been examined. NADPH oxidation was inhibited $50 \%$ by cyanide $\left(2 \times \mathrm{IO}^{-2} \mathrm{M}\right)$, rotenone $\left(\mathrm{IO}^{-4} \mathrm{M}\right)$; antimycin $\mathrm{A}$, amytal and azide were markedly less inhibitory. NADPH:ferrocytochrome $c$ oxidoreductase, NADPH:menadione oxidoreductase, ferrocytochrome $c$ : oxygen oxidoreductase and succinic dehydrogenase were detected. A phosphorylation ( $0.4 \mathrm{nmoles} / \mathrm{min} . / \mathrm{mg}$.), associated with NADPH oxidation, was measured, NADPH could be replaced by NADP and isocitrate. This phosphorylation was absolutely dependent upon oxygen and was inhibited $25 \%$ by carbonyl cyanide $p$-trifluoromethoxyphenylhydrazone $(5 \mu \mathrm{M})$.
\end{abstract}

Blue-green algae, in common with other autotrophic micro-organisms, are capable of growth in an inorganic environment. However, autotrophs will utilize to some extent reduced carbon compounds (Carr \& Pearce, I966; Hoare, Hoare \& Moore, 1967; Kelly, I967; Smith, London \& Stanier, 1967; Pearce \& Carr, 1967, 1969) and it is their dependence upon a specific energy source (an inorganic oxidation or photosynthesis) that distinguishes them most clearly from heterotrophic bacteria. Typically, growth and respiratory rates do not increase when organic substrates are supplied to obligate autotrophs. However, when the rate of respiration of Anabaena variabilis is reduced by prior starvation of $\mathrm{CO}_{2}$, oxygen uptake is partially restored by addition of glucose (Kratz \& Myers, I955; Pearce \& Carr, 1967). Although respiratory rates in blue-green algae are low, $Q_{\mathrm{o}_{2}}$ values of 5 to Io being common, some respiration does occur; its inhibition by cyanide, azide or carbon monoxide suggests an electron transport chain at least comparable to that found in aerobic bacteria (Webster \& Frankel, 1953).

The observation by Smith et al. (1967) that obligate chemoautotrophs and blue-green algae lack an NADH oxidase led these workers to suggest that such a metabolic lesion is the characteristic and general feature of obligately autotrophic micro-organisms. However, oxidation of reduced pyridine nucleotides by extracts of autotrophic thiobacilli (Hempfling \& Vishniac, 1965; Trudinger \& Kelly, 1968) and blue-green algae (Horton, 1968; Leach \& Carr, 1968) suggests that these organisms can oxidize organic substrates, and is consistent with their low but reproducible respiratory oxygen uptake. Furthermore, in Anabaena variabilis the coupling in the dark of NADPH oxidation to ATP synthesis has been shown in cell-free extracts (Leach \& Carr, I969) 
and a proton translocation, outwards through the membrane, in response to oxygenation of intact cells has been found (Scholes, Mitchell \& Moyle, 1969). In view of the lack of information on the respiratory activity of blue-green algae and because of the relevance of such data to the understanding of autotrophic physiology, a study of respiratory enzymes and oxidative phosphorylation in $A$. variabilis is here presented. Preliminary accounts of some of these results have been reported elsewhere (Leach $\&$ Carr, I968, 1969).

\section{METHODS}

Growth of Anabaena variabilis. Organisms were grown autotrophically in light as previously described (Pearce \& Carr, 1967) and were harvested by centrifugation in the late log phase of growth.

Preparation of cell-free extracts. Three procedures were employed. Unless otherwise stated, method $(a)$ was used for the preparation of extracts in which electron-transport enzymes were measured, and method $(b)$ for phosphorylation studies.

(a) A suspension of washed organisms (50 to $100 \mathrm{mg}$. dry wt $/ \mathrm{ml}$.) in $0 . \mathrm{I}$ M-potassium phosphate buffer, $\mathrm{pH} 7 \cdot 6$ was subjected to ultrasonic treatment (M.S.E. $100 \mathrm{~W} 20$ $\mathrm{KHz}$ instrument) for three $45 \mathrm{sec}$. periods at $0^{\circ}$ under a constant stream of nitrogen. Cell debris was removed by centrifugation at $10,000 \mathrm{~g}$ for $\mathrm{I} 5 \mathrm{~min}$. Cell breakage under oxygen-free nitrogen yielded extracts several times more active with regard to NADH and NADPH oxidases.

(b) A suspension of washed organisms (50 to $250 \mathrm{mg}$. dry wt $/ \mathrm{ml}$.) in sorbitol, 330 mM; HEPES, Io mM; $\mathrm{MgCl}_{2}$, I mM; EDTA, I mM; pH 7.6 (hereafter called 'HEPES buffer') was incubated with lysozyme ( $0^{\cdot} \mathrm{I} \mathrm{mg}$. $/ \mathrm{ml}$.) at $20^{\circ}$ for $20 \mathrm{~min}$. and then extruded through a pre-cooled French pressure cell (Aminco Instrument Co. Inc., Silver Spring, Maryland, U.S.A.) at $500 \mathrm{lb}$./in. ${ }^{2}$ Debris was removed by centrifugation at $5000 \mathrm{~g}$ for Io min. Material was further fractionated as described in Results section.

(c) A suspension of washed organisms ( 150 to $250 \mathrm{mg}$. dry wt/ml.) in HEPES buffer, $\mathrm{pH} 7 \cdot 6$, was added to an equal volume of washed sand and ground with a mortar and pestle for $15 \mathrm{~min}$. at $\mathrm{o}$ to $4^{\circ}$. The sand was removed by centrifuging at $2000 \mathrm{~g}$ for $10 \mathrm{~min}$. and the suspension of broken organisms was then centrifuged at $10,000 \mathrm{~g}$ for $15 \mathrm{~min}$. to remove unbroken cells and cell-wall debris.

Fractionation of cell-free extracts of Anabaena variabilis. The fractionation of a suspension of disintegrated Anabaena variabilis by differential centrifugation is summarized in Fig. I.

Conditions and extinction values employed in enzyme assays. The spectrophotometric determinations described below were carried out using an Optica CFR4 or a Unicam SP 800 recording spectrophotometer at $34^{\circ}$ in silica cuvettes $(d=\mathrm{I} \mathrm{cm}$.). Owing to the relatively dense cell-free extracts employed it was sometimes necessary to use the maximum energy of incident light available in the spectrophotometer, which resulted in an increased background 'noise' level; slow chart speeds ( $1 \mathrm{~cm} . / \mathrm{min}$.) were also necessary to measure enzymic rates. Ferrocytochrome $c$ was oxidized by ferricyanide and reduced by dithionite and dialysed against four changes of water at $4^{\circ}$. Quinones (menadione and vitamin $\mathrm{K}_{1}$ ) were dissolved in ethanol and diluted with water to the required concentration. Brief ultrasonic treatment assisted in the even suspension of these compounds. Extinction coefficients $\left(E_{1 \mathrm{~ms}}^{\mathbf{1} \mathrm{m}}\right)$ employed were: NADPH and NADH, 6.2 at $340 \mathrm{~nm}$.; ferrocytochrome $c \mathrm{red} / \mathrm{ox}, 19$ at $550 \mathrm{~nm}$. (Haas, I955); vitamin $\mathrm{K}_{1}$, 
0.258 at $245 \mathrm{~nm}$. The latter value was kindly supplied by Dr P. J. Dunphy of this department. Amytal, rotenone and antimycin A were dissolved in ethanol; control assays showed that the ethanol at the concentration employed did not affect the enzyme examined. Anaerobic measurements were carried out in a spectrophotometer cuvette, modified to act as a Thunberg tube, that had been evacuated and gassed three times with oxygen-free nitrogen.

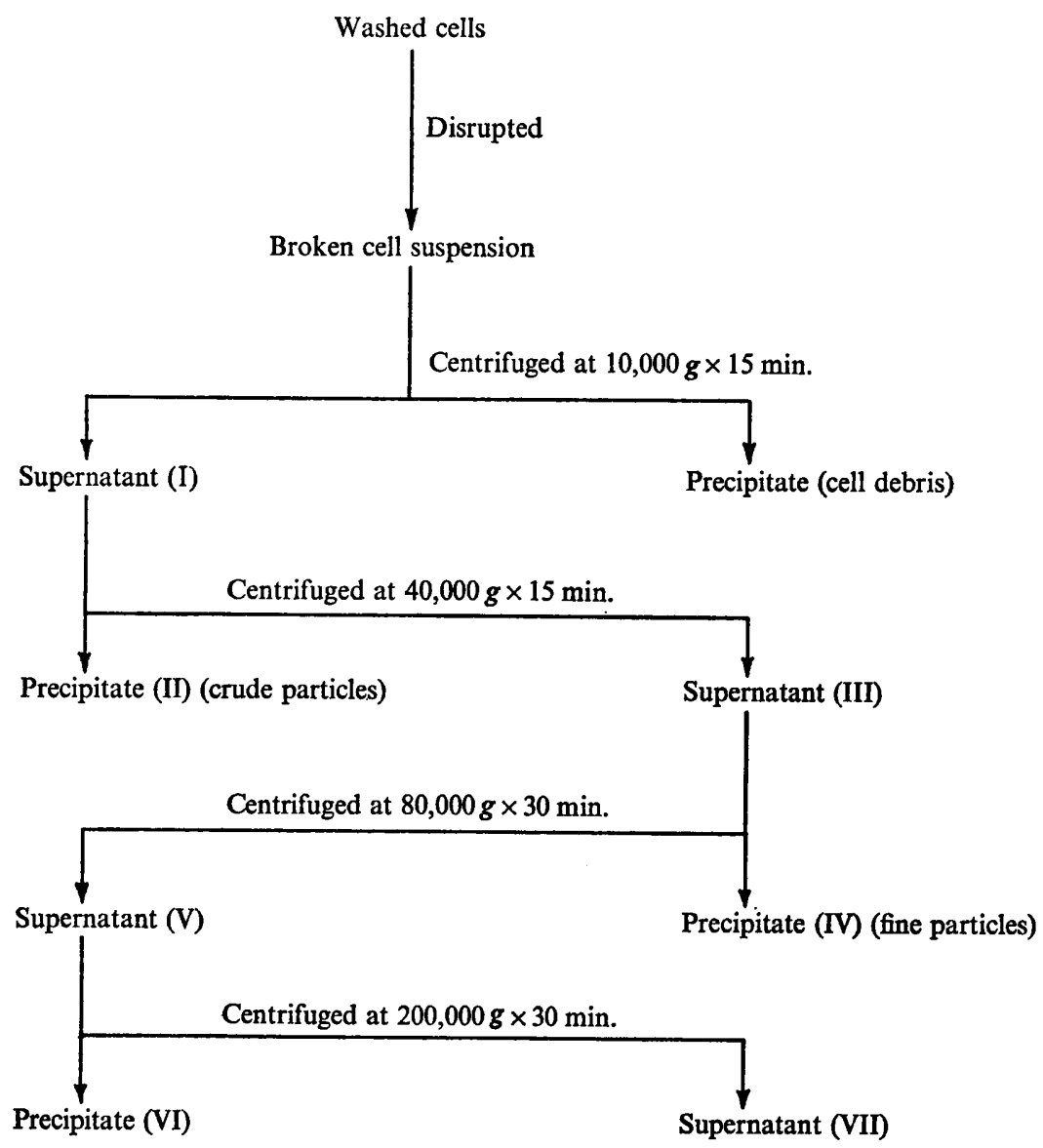

Fig. I. Flow sheet of the subcellular fractionation of Anabaena variabilis.

\section{Reduced pyridine nucleotide oxidase (NADPH:oxidoreductase)}

Spectrophotometric measurement. Cuvettes contained in $3 \mathrm{ml}$.: potassium phosphate, $\mathrm{pH} 7 \cdot 6,200 \mu$ moles; NADPH, $0.3 \mu$ mole and cell-free extract ( 0.5 to $5 \mathrm{mg}$. protein). The decrease in $E_{340}$ in the experimental cuvette was measured against a boiled enzyme control.

Measurement by $\mathrm{O}_{2}$ uptake. Oxygen consumption was measured using a Clark electrode (Yellow Springs Instrument Co. Inc.). The reaction mixture contained in

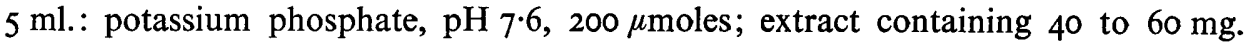
microbial protein, and $10 \mathrm{mg}$. NADPH added to start the reaction. The rate of backdiffusion of oxygen into the electrode cell was corrected for, as were blank determinations without NADPH or with boiled enzyme. 
Transhydrogenase (EC I.6.I.I)

Acetyl pyridine analogue procedure (Kaplan, 1967). Potassium phosphate $\mathrm{pH} 7 \cdot 6$, $66 \mu$ moles; NADPH, $0.5 \mu$ moles and $\mathrm{KCN}, 20 \mu$ moles were added to cell-free extract of Anabaena variabilis ( 5 to $10 \mathrm{mg}$. protein) in I ml. final volume. After the addition of acetyl pyridine $\mathrm{NAD}^{+}$, the increase in extinction at $375 \mathrm{~nm}$. was measured.

Coupling with pig heart isocitrate dehydrogenase (Kaplan, 1955). The reaction mixture containing, in $3 \mathrm{ml}$., $\mathrm{NADP}^{+}, 0 \cdot \mathrm{I} \mu$ mole; potassium phosphate, $\mathrm{pH} 7 \cdot 6$, Ioo $\mu$ moles and isocitrate dehydrogenase ( $0.1 \mathrm{mg}$.; sp. act. $9.8 \mu$ moles, min. ${ }^{-1}, \mathrm{mg}^{-1}$ ) was allowed to proceed to completion after the addition of isocitrate (Io $\mu$ moles) with the small amount of $\mathrm{NADP}^{+}$present, and then $\mathrm{NAD}^{+}$( $\mathrm{r} \mu$ mole) was added. After incubation for a few minutes (any transhydrogenase would then be detected) extract of Anabaena variabilis ( 2 to $5 \mathrm{mg}$. protein) was added. Increase in absorption at $340 \mathrm{~nm}$. was assumed to be due to the transfer of hydrogen from NADPH to NAD ${ }^{+}$thus releasing $\mathrm{NADP}^{+}$for further reduction. Extracts of $A$. variabilis contain no detectable $\mathrm{NAD}^{+}$-active isocitrate dehydrogenase (Pearce \& Carr, ${ }^{9667)}$.

NADPH (NADH): Ferrocytochrome c oxidoreductase (EC I.6.9.3). Cuvettes contained in $3 \mathrm{ml}$.: potassium phosphate, $\mathrm{pH} 7 \cdot 6,200 \mu$ moles; KCN, $20 \mu$ moles; NADPH or NADH, $0.3 \mu$ moles and cell-free extract ( 0.5 to $2.0 \mathrm{mg}$. protein). The reaction was started by the addition of oxidized ferrocytochrome $c(0 \cdot 2 \mu$ mole) to each cuvette and the increase in $E_{550}$ measured against the blank lacking NADPH.

$N A D P H(N A D H)$ : menadione oxidoreductase (EC I.6.99.2). The oxidation of NADPH in the presence of menadione was observed at $340 \mathrm{~nm}$. Cuvettes contained in $3 \mathrm{ml}$.: KCN, $20 \mu$ moles; NADPH, $0.3 \mu$ moles; potassium phosphate, $\mathrm{pH} 7 \cdot 6,200 \mu$ moles, and cell-free extract $(0.5$ to $2.0 \mathrm{mg}$. protein). The reaction was started by the addition of menadione ( $0.5 \mu$ mole) to the experimental cuvette. The enzyme was also measured with vitamin $\mathrm{K}_{1}$ used in place of menadione, in which case the increase of $E_{245}$ due to vitamin $\mathrm{K}_{1}$ reduction was measured as well as the decrease of $E_{340}$ due to pyridine nucleotide oxidation.

Ferrocytochrome $c$ : oxygen oxidoreductase (EC I.9.3.r). Oxidation of reduced ferrocytochrome $c$ was measured by decrease in $E_{550}$. Cuvettes contained in $3 \mathrm{ml}$.: potassium phosphate, $\mathrm{pH} 7.6$ ( $200 \mu$ moles) and 2 to $4 \mathrm{mg}$. algal protein. 50 nmoles reduced ferrocytochrome $c$ were added to the experimental cuvettes.

Succinic dehydrogenase (EC I.I.99.I). This assay was carried out as previously described (Pearce, Leach \& Carr, 1969).

\section{The oxidative synthesis of ATP by extracts of Anabaena variabilis}

The synthesis of ATP coupled with the oxidation of reduced pyridine nucleotides and organic substrates was determined by a modification of a procedure of Avron (I960). The standard reaction mixture, in a total volume of I ml., contained in $\mu$ moles: sorbitol, 330 ; [ $\left.{ }^{32} \mathrm{P}\right]$ sodium phosphate, I (specific radioactivity, $\mathrm{I} \cdot 5$ to $2 \cdot 5 \mu \mathrm{Ci} / \mu$ mole); HEPES buffer $\mathrm{pH} 7 \cdot 6, \mathrm{I0} ; \mathrm{MgCl}_{2}, \mathrm{I}$; EDTA, I; ADP, I ; extract (I.5 to $4^{\circ} \cdot \mathrm{mg}$. protein); and NADPH, NADH (I.5 $\mu$ mole) or organic substrates ( $20 \mu$ moles) and $\mathrm{I} \cdot 5 \mu$ mole of $\mathrm{NADP}^{+}$and $\mathrm{NAD}^{+}$. Appropriate controls were assayed, omitting the oxidized nucleotides or organic substrates. The reactions were allowed to proceed in the dark for Io min. at $34^{\circ}$ and were terminated by the addition of $0 . \mathrm{I} \mathrm{ml}$. of $20 \%(\mathrm{w} / \mathrm{v})$ trichloroacetic acid. The precipitated protein was separated by centrifugation and 
$0.3 \mathrm{ml}$. samples of the supernatants were used for ATP measurement. Subsequent steps were carried out at 0 to $2^{\circ}$.

Acetone (I.2 ml.) was added to each sample, mixed, allowed to stand for Io min., and the water content of each tube was then made up to $2.5 \mathrm{ml}$. with water saturated with isobutanol + benzene (I:I) mixture. Seven $\mathrm{ml}$. of isobutanol + benzene (I:I) saturated with water was added and thoroughly mixed. After phase separation, $0.8 \mathrm{ml}$.

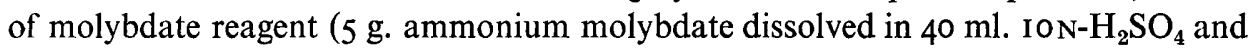
made up to $100 \mathrm{ml}$. with water) was run down the side of each tube and the water layer was mixed gently. After allowing to stand for $5 \mathrm{~min}$., the contents were mixed thoroughly for $30 \mathrm{sec}$. and allowed to stand. After phase separation, the upper layer which contained the majority of ${ }^{32} \mathrm{P}^{3} \mathrm{PO}_{4}$ molybdate complex was removed and 0.02 $\mathrm{ml}$. of $0.02 \mathrm{M}-\mathrm{KH}_{2} \mathrm{PO}_{4}$ were added to the aqueous layer, followed by $7.0 \mathrm{ml}$. of the isobutanol:benzene mixture saturated with water. After re-extraction of the phosphate molybdate complex, the isobutanol:benzene phase was removed. Some of the aqueous phase was placed in a stainless steel planchet and the $\left[{ }^{32} \mathrm{P}\right]$ content counted in a Nuclear Chicago gas flow counter at an efficiency of $33 \%$ to an accuracy of at least $0.5 \%$. Samples of the aqueous phase were also used in chromatographic determinations.

The use of $\left[{ }^{32} \mathrm{P}\right] A T P$ in glucose-6-phosphate formation. To link the [ $\left.{ }^{32} \mathrm{P}\right] \mathrm{ATP}$ synthesized to hexokinase activity, $\mathrm{I} 5$ i.u. of hexokinase (E.C. 2.7. I I) and glucose ( $5 \mu$ moles) were added to the standard phosphorylation mixture. After incubation, the reaction was stopped by the addition of $0 . \mathrm{I} \mathrm{ml}$. of $20 \%$ trichloroacetic acid and the remaining $\left[{ }^{32} \mathrm{P}_{\mathrm{PO}_{4}}\right.$ removed as a molybdate complex as described above. $\left[{ }^{32} \mathrm{P}\right]$ present in the glucose-6-phosphate formed was assayed after chromatographic separation.

Chromatography of $\left[{ }^{32} P\right] A T P$ and $\left[{ }^{32} P\right]$ glucose-6-phosphate. Chromatographic separations were achieved on thin layer cellulose plates and on paper (Whatman no. I) and radioactive peaks were measured on a Nuclear Chicago Actiograph III scanner. Solvents used for the separation of ATP were: isobutyric acid +water $(7+5+3$, by vol.); $n$-propanol + water + trichloroacetic acid + ammonia $(75+20+5+0 \cdot 3$, by vol.) (see Block, Durrum \& Zweig, 1968). Inorganic phosphate, AMP, ADP, and ATP were chromatographed as standards and were located by molybdate reagent or the unstained nucleotides were observed when viewed under u.v. light. Glucose-6phosphate was chromatographed in methanol + ammonia + water $(6+\mathrm{I}+3$, by vol. $)$ and in methanol + formic acid + water $(80+15+5$, by vol.) (see Block et al. 1968).

Protein determination. A modified biuret reaction was used (Pearce \& Carr, 1967).

Chlorophyll and phycocyanin determinations. Spectra of diluted extracts were measured between $400 \mathrm{~nm}$. and $700 \mathrm{~nm}$. and the extinction of chlorophyll was measured at $663 \mathrm{~nm}$. and that of phycocyanin $c$ at $620 \mathrm{~nm}$. Extinction values were not converted to weight of material present.

Determination of ATP by a luciferin: luciferase assay system. The assay procedure was a simplification of the method of Lyman \& DeVincenzo (1967). A modified singlesided Locarte fluorometer MK I I was used in a dark room. The photomultiplier tube was dismantled from its housing and a plate with a small mirrored chamber and a Io $\mathrm{mm} . \times 80 \mathrm{~mm}$. spectrophotometric tube attached was fitted. The standard reaction mixture in $\mathrm{I} .55 \mathrm{ml}$. contained glycine buffer at $\mathrm{pH} \mathrm{8.0} \mathrm{(I00} \mu$ moles) and $\mathrm{MgCl}_{2}(2 \mu$ moles). Commercial ATP samples at a suitable dilution were added in $0.2 \mathrm{ml}$. of solution. Readings on the instrument's galvanometer were recorded and then $0.25 \mathrm{ml}$. 
of firefly lantern extract ( $10 \mathrm{mg}$. firefly tails homogenized in $10 \mathrm{ml}$. of glycine buffer and filtered) were rapidly injected into the tube by means of a syringe. The maximum reading on the galvanometer for each ATP sample was recorded and a standard relationship between this and the ATP supplied was constructed. This procedure could be employed only with purified ATP samples, owing to quenching by other co-factors.

Chemicals and enzymes. Nucleotides, pig heart isocitrate dehydrogenase and hexokinase were purchased from Boehringer und Soehne G.m.b.H., Mannheim, Germany; horse ferrocytochrome $c$ from Seravac Ltd, Maidenhead, Berkshire, [ ${ }^{32}$ P]phosphate from The Radiochemical Centre, Amersham, Buckinghamshire; firefly tails and acetyl pyridine nucleotide from Sigma (London) Ltd; amytal and antimycin A from KochLight Ltd, Colnbrook, Buckinghamshire. Vitamin $\mathrm{K}_{1}$ was kindly given by Dr P. J. Dunphy (of this department), and FCCP was a gift from Dr P. Scholes (Glyn Research Laboratories, Bodmin, Cornwall).

Abbreviations. Non-standard abbreviations used: EDTA, ethylene-diaminetetraacetic acid disodium salt; HEPES, $N$-2-hydroxyethyl-piperazine- $N^{\prime}$-2-ethanesulphonic acid; FCCP, carbonylcyanide $p$-tri-fluoromethoxyphenylhydrazone.

\section{RESULTS}

Oxidative activities of cell-free extracts. NADPH and NADH oxidases were detected in cell-free extracts of Anabaena variabilis, and after fractionation as described in Fig. I these activities were distributed throughout the supernatant fractions and were present at highest specific activity in fraction VII. After breaking $A$. variabilis by grinding with sand in HEPES buffer, the partial localization of NADPH oxidase in the particulate fractions II and IV was observed (Table I). The supernatant fraction VII prepared from ultrasonic treated cells contained some NADPH oxidase activity but no chlorophyll, demonstrating a complete separation of chlorophyll from part of the oxidase activity. Most of the oxidase activity, however, sedimented with the chlorophyll-containing fractions and with extracts prepared from cells ground in sand the oxidase was confined to the heavy fractions along with the chlorophyll. The sedimentation characteristics of NADPH and NADH oxidase were similar, and the activity with both coenzymes present was not greater than with NADPH alone. NADH oxidase activity varied between $40 \%$ and $65 \%$ of the NADPH oxidase in all extracts assayed. Transhydrogenase activity could not be detected by the acetyl pyridine analogue procedure of Kaplan (1967) but a low rate (0.3I nmole/min./mg.) was detected using this method coupled with pig heart isocitrate dehydrogenase (Kaplan, I955). In subcellular fractions prepared from ultrasonic treated extracts succinic dehydrogenase showed a broad distribution of activity, similar to that of NADPH oxidase (see Table I). Confirmation that the oxidations of reduced pyridine nucleotides were by true oxidases was given by lack of activity under anaerobic conditions (Fig. 2a). After oxidation the NADP+ was re-reduced by the action of isocitrate dehydrogenase when isocitrate (Io $\mu$ moles) was added to the cuvette (Fig. $2 b$ ), which indicated that the initial decrease in $E_{340 \mathrm{~mm}}$ could be attributed to an oxidase activity and not to the destruction of the nucleotide. NADPH oxidase had a broad $\mathrm{pH}$ optimum around $7 \cdot 6$, although a limited activity could be detected at $\mathrm{pH} 9 \cdot 0$ (Fig. $3 a$ ). NADPH oxidation by cell-free extracts showed marked dependence on temperature, the rate at $34^{\circ}$ being 


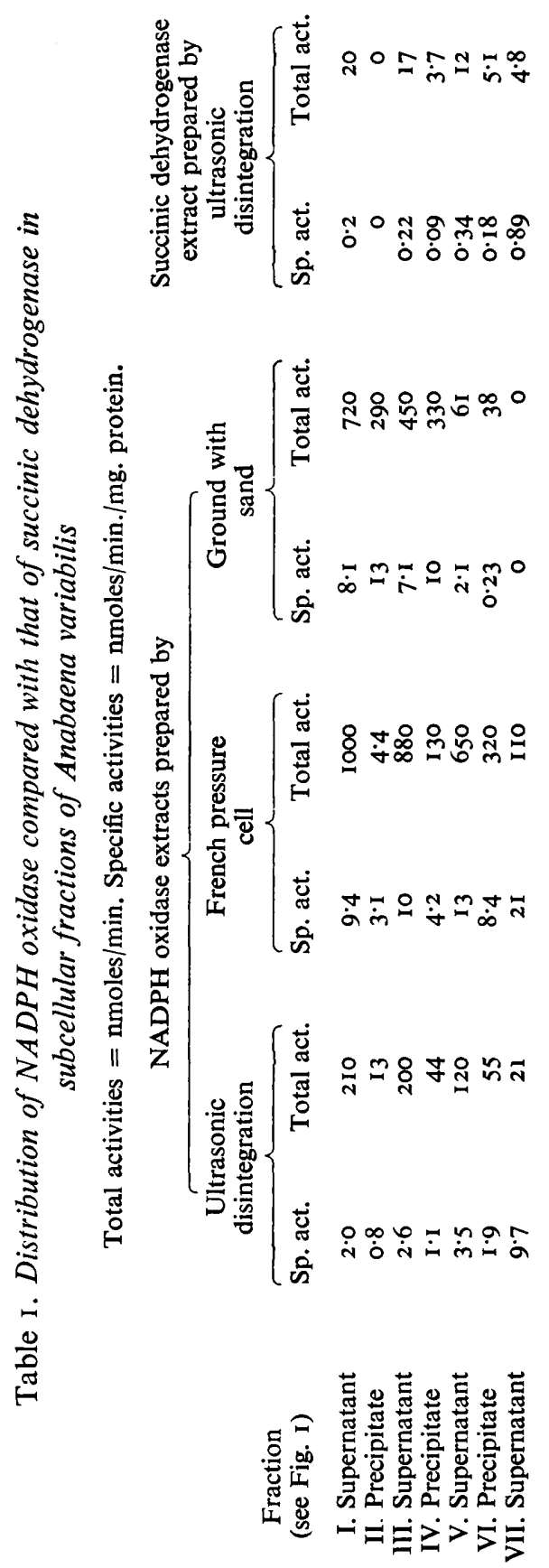


several times faster than at room temperature. Maximal rates were obtained at 37 to $39^{\circ}$ (Fig. $3 b$ ).

The electron-transfer pathway of NADPH oxidase was examined in extracts of Anabaena variabilis by the assay of component enzymes and by the effect of inhibitors
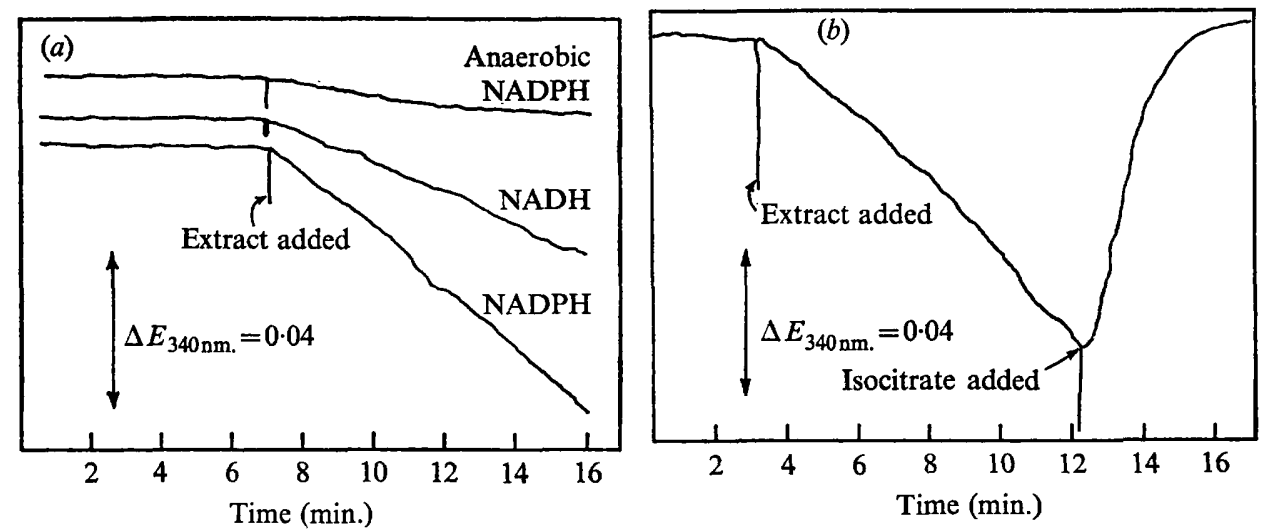

Fig. 2a. Spectrophotometric traces showing the aerobic oxidation of NADPH and NADH by ultrasonicated extracts of Anabaena variabilis. Cuvettes contained $2.8 \mathrm{mg}$. protein (for further details see Methods).

Fig. $2 b$. The regeneration of NADPH after its aerobic oxidation by an extract of Anabaena variabilis following the addition of isocitrate (ro $\mu$ moles). The cuvette contained $3.4 \mathrm{mg}$. protein (for further details see Methods). NADPH was excluded from the blank cuvette.
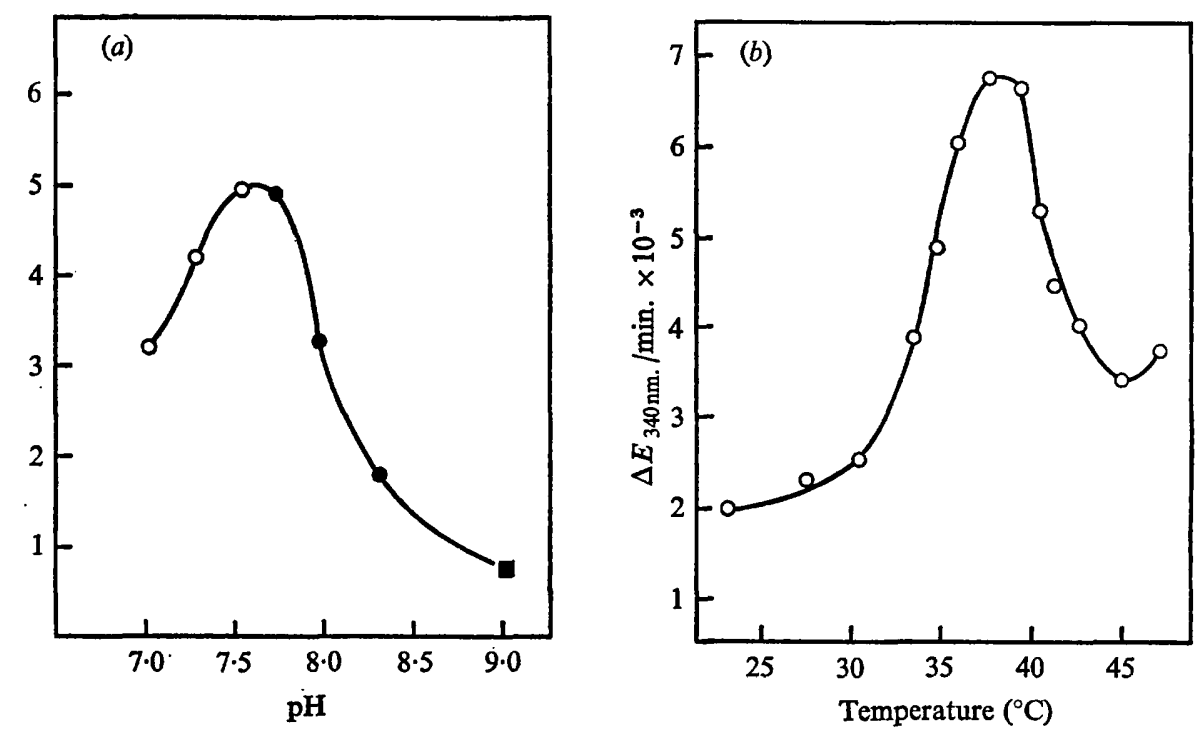

Fig. $3 a$. pH dependence of NADPH oxidase activity in ultrasonicated cell-free extracts of Anabaena variabilis. Cuvettes contained $2 \mathrm{mg}$. protein and buffer (I00 $\mu$ moles). $\bigcirc$, Phos-

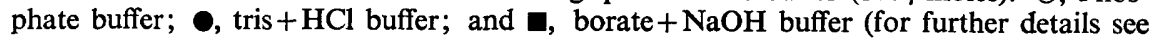
Methods).

Fig. $3 b$. The effect of temperature on the rate of NADPH oxidase from ultrasonicated cellfree extracts of Anabaena variabilis. Cuvettes contained I. $2 \mathrm{mg}$. protein and were preequilibrated for 5 to $6 \mathrm{~min}$. before the addition of reduced pyridine nucleotide. (For further details see Methods.) 

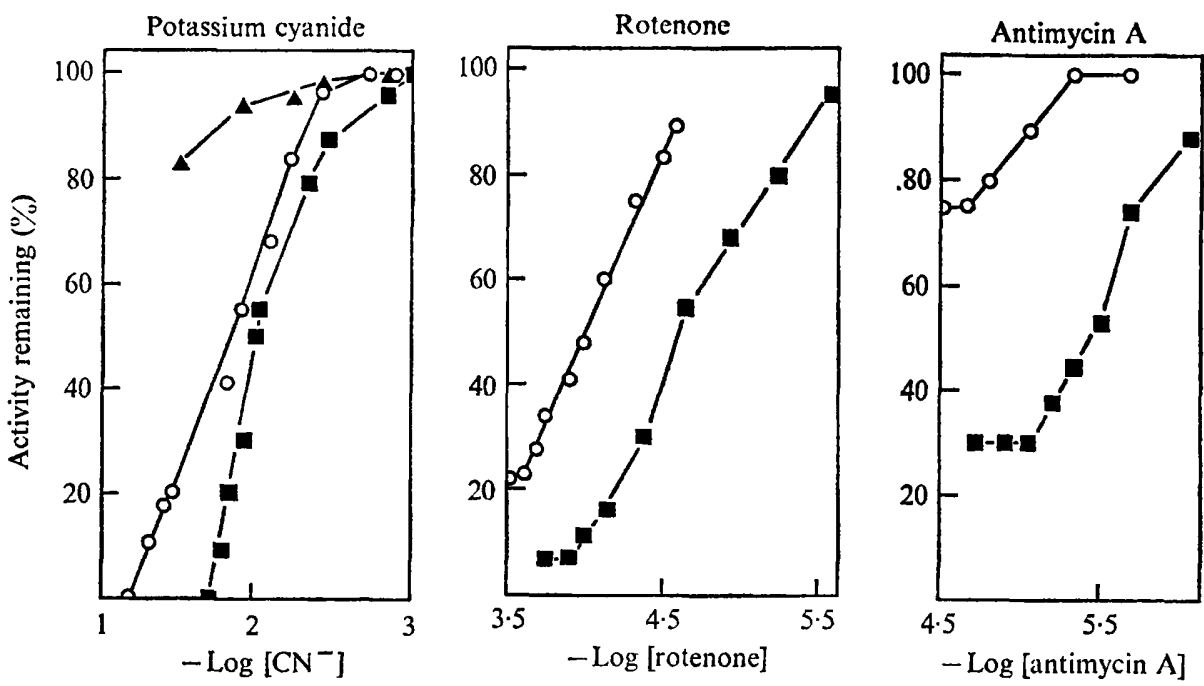

Fig. 4. The effect of inhibitors on electron transport activities of cell-free extracts of Anabaena variabilis. Reaction mixtures as described in Methods and the inhibitors were added in a small volume $(0.2 \mathrm{ml}$.). The figures show the \% of electron transport activities remaining against $-\log$ of molar concentration of the inhibitor; $O, N A D P H$ oxidase; $\square$, NADH oxidase: $\Delta, \mathrm{NADPH}+$ cytochrome $c$ reductase.

\section{Table 2. Electron transport activities present in extracts of Anabaena} variabilis prepared by ultrasonic treatment

Reduced pyridine nucleotide: oxidase (by $E_{340 \mathrm{~nm} .}$ )

Reduced pyridine nucleotide: oxidase (by $\mathrm{O}_{2}$ uptake)

*Reduced pyridine nucleotide: cytochrome $c$ reductase (by $E_{340 \mathrm{~nm} .}$ )

*Reduced pyridine nucleotide: cytochrome $c$ reductase (by $E_{550 \mathrm{~mm}}$ )

Reduced pyridine nucleotide: menadione reductase (by $E_{340 \mathrm{~nm}}$.)

Reduced pyridine nucleotide: vitamin $\mathrm{K}_{1}$ reductase (by $E_{340 \mathrm{~nm}}$ )

Reduced pyridine nucleotide:vitamin $\mathrm{K}_{1}$ reductase (by $E_{\mathbf{3 4 0 \mathrm { mm }} \text {.) }}$ )

Transhydrogenase

*Cytochrome $c$ oxidase (by $E_{550 \mathrm{~nm}}$ )

Succinic dehydrogenase

$\overbrace{\begin{array}{c}\text { NADPH } \\ \text { (nmole/min./ } \\ \text { mg. protein) }\end{array}}^{\text {Electron donor }} \begin{gathered}\text { NaDH } \\ \text { mole/min./ protein) }\end{gathered}$

Enzyme activities were measured as in Methods, the particular procedure employed being indicated in parentheses. Enzyme activities are expressed as nmoles $/ \mathrm{min}$. $/ \mathrm{mg}$. protein and are the mean of at least three determinations.

* These rates are from extracts that had been dialysed against phosphate buffer (see Results).

on oxidation and reduction rates. The activities of respiratory enzymes were consistently higher with NADPH than with NADH, and only the former values will be discussed in detail.

Electron-transfer reactions that were detected in cell-free fractions are summarized in Table 2. The rates of NADPH-menadione reductase and NADPH-vitamin $K_{1}$ 
reductase showed a dependence on the concentration of quinone. Maximal rates were obtained with quinone concentrations greater than $2 \mathrm{~mm}$. When oxidized ferrocytochrome $c$ was added to extracts that had been stored at $-18^{\circ}$ for 3 days, it was immediately reduced without the addition of an electron donor; after dialysis of such extracts, the reduction of ferrocytochrome $c$ required an electron donor. Thus dialysis permitted the measurement of both NADPH:ferrocytochrome $c$ reductase and ferrocytochrome $c$ oxidase in stored extracts.

The rates of reduction of ferrocytochrome $c$, menadione and vitamin $\mathrm{K}_{1}$ by NADPH were all greater than the overall NADPH oxidase activity. The rate of activity of cytochrome $c$ oxidase was similar to that of NADPH oxidase. With NADH as the

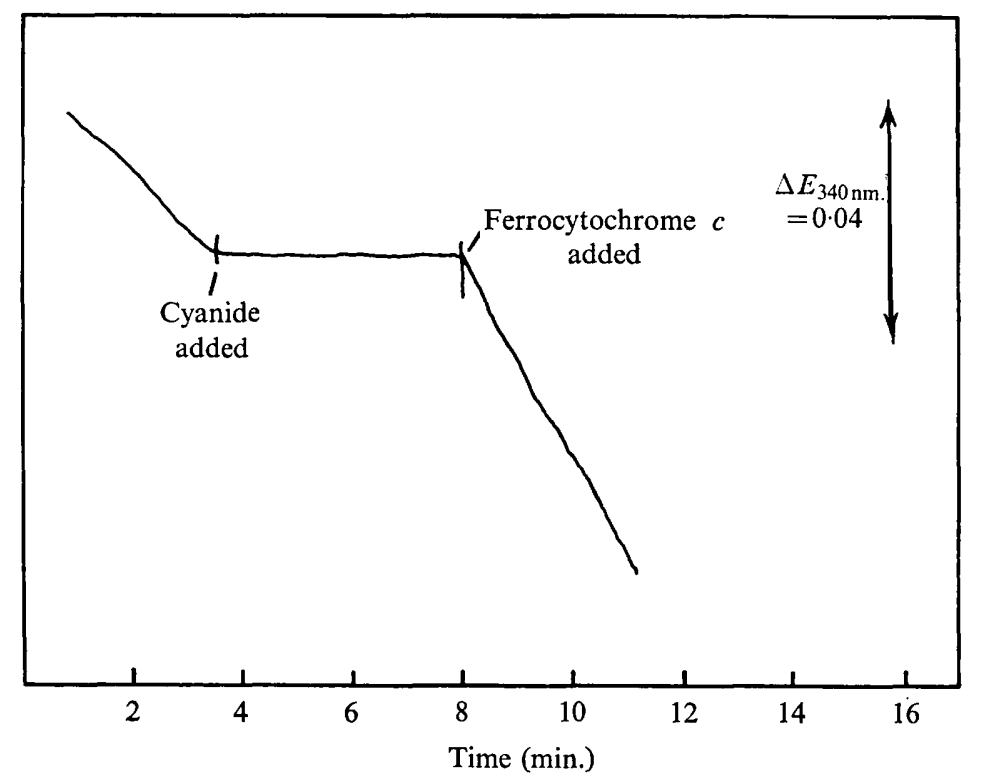

Fig. 5. The release of cyanide inhibition of NADPH oxidation in extracts of Anabaena variabilis following the addition of ferrocytochrome $c$ ( $0.2 \mu$ moles). The cuvette contained $3.4 \mathrm{mg}$. protein (further details as in Methods); NADPH was excluded from the blank cuvette.

electron donor, the rate of reduction of the quinones and ferrocytochrome $c$ were of the same order as the NADH oxidase activity, which was about half that of NADPH oxidase.

Effects of inhibitors on electron transport activities (Fig. 4). Relatively high levels of inhibitors were necessary to demonstrate inhibition. Thus total inhibition of NADPH oxidase was obtained with $5 \times 10^{-2} \mathrm{M}$-cyanide; NADH oxidase was completely inhibited by $2 \times 10^{-2} \mathrm{M}$-cyanide. NADH oxidase activity was ten times more sensitive to inhibition by antimycin A than was NADPH oxidase; rotenone was several times more effective against NADH oxidase than NADPH oxidase. Amytal ( $\left.\mathrm{IO}^{-3} \mathrm{M}\right)$ inhibited the NADH oxidase activity by approximately $50 \%$; sodium azide $10^{-3} \mathrm{M}$ had little effect on either oxidase. NADPH: ferrocytochrome reductase was not affected by cyanide, but ferrocytochrome $c$ oxidase was as sensitive to cyanide as was the reduced pyridine nucleotide oxidase. The release of the cyanide inhibition of NADPH oxidation by ferrocytochrome $c$ is shown in Fig. 5 . 
When extracts were incubated with oxidized ferrocytochrome $c$ and $\mathrm{NADH}$, in the absence of cyanide, no net accumulation of reduced ferrocytochrome $c$ was detected spectrophotometrically. However, with NADPH as electron donor, there was an accumulation of reduced cytochrome $c$ which was detected as an increase in optical density at $550 \mathrm{~nm}$. The redox dye, phenolindo-2,6-dichlorophenol was also rapidly reduced by NADPH ( $90 \mathrm{nmoles} / \mathrm{min} . / \mathrm{mg}$. protein) but the rate with NADH was substantially less (I·02 nmoles/min./mg.).
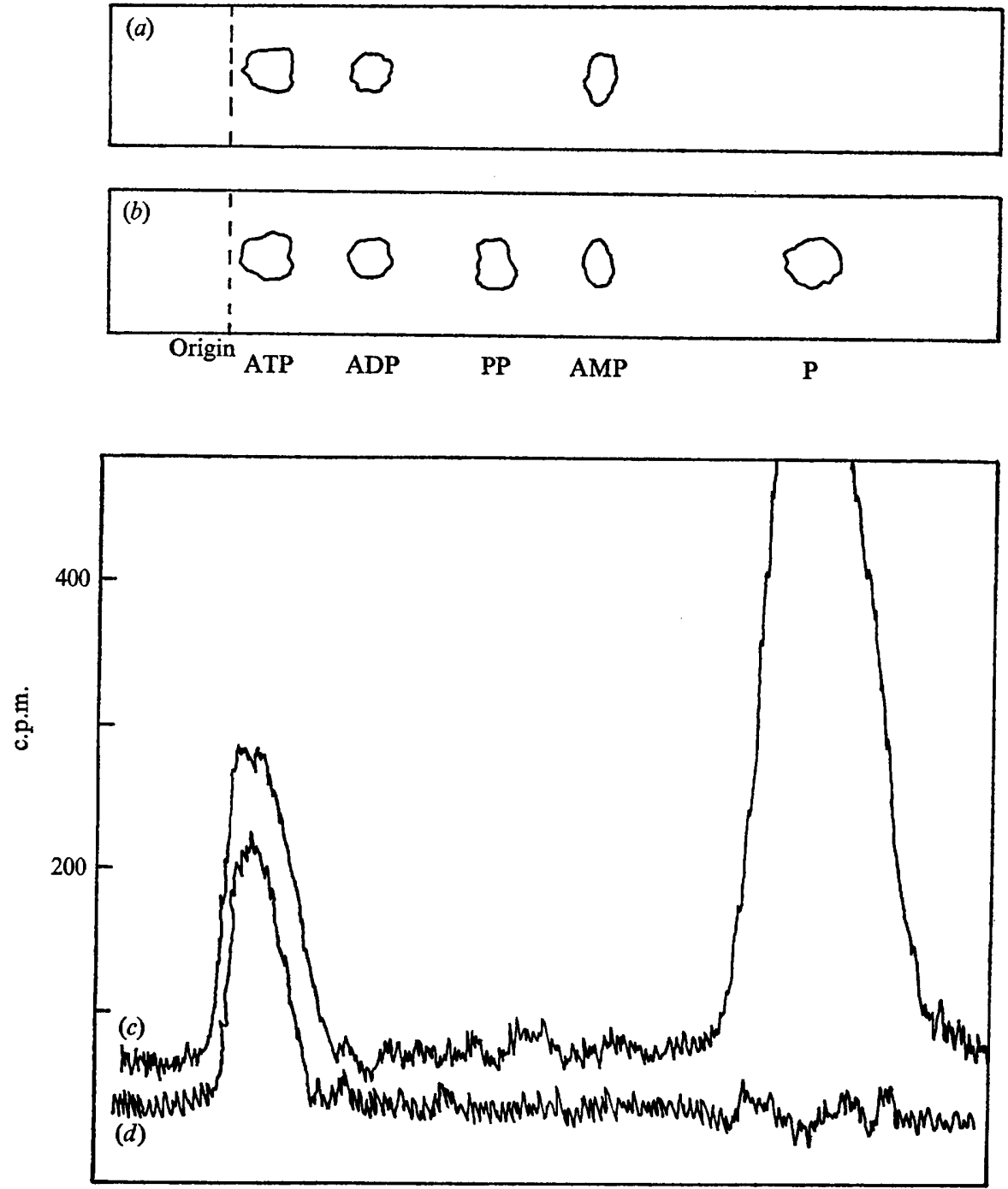

Fig. 6. The separation of [32P]ATP and [ $\left.{ }^{32} \mathrm{P}\right]$ inorganic phosphate by paper chromatography.

The chromatographic separation of adenosine nucleotides and inorganic phosphate using $n$-propanol $+\mathrm{H}_{2} \mathrm{O}+$ trichloroacetic acid + ammonia $22(75+20+5+0 \cdot 3)$ as the developing solvent. The $R_{F}$ value for inorganic phosphate was 0.65 . After developing the chromatogram (a) shows the spots seen under u.v. light and $(b)$ shows the spots that develop with molybdate spray for phosphates. The radioactive traces were obtained, using an Actiograph III strip scanner (see Methods). Trace (c) shows the position of label before extraction of inorganic phosphate as a molybdate complex and trace $(d)$ after extraction of inorganic phosphate. 
Oxidative phosphorylation. When cell-free preparations of Anabaena variabilis were incubated in the dark under the conditions described in Methods for oxidative phosphorylation studies, there was a net accumulation of esterified $\left[{ }^{32} \mathrm{P}\right]$ phosphate which co-chromatographed with ATP (Fig. 6). The initial rate of ATP synthesis, when extracts were incubated with NADPH, was linear with time (Fig. 7) and corresponded to a rate of $0.43 \pm 0.06 \mathrm{nmoles}$ of ATP formed $/ \mathrm{min}$. $/ \mathrm{mg}$. of protein. NADPH was twice as effective as NADH as a source of electrons whose oxidation was linked to phosphorylation. When the potent uncoupling agent FCCP ( $5 \mu$ moles) was included in the reac-

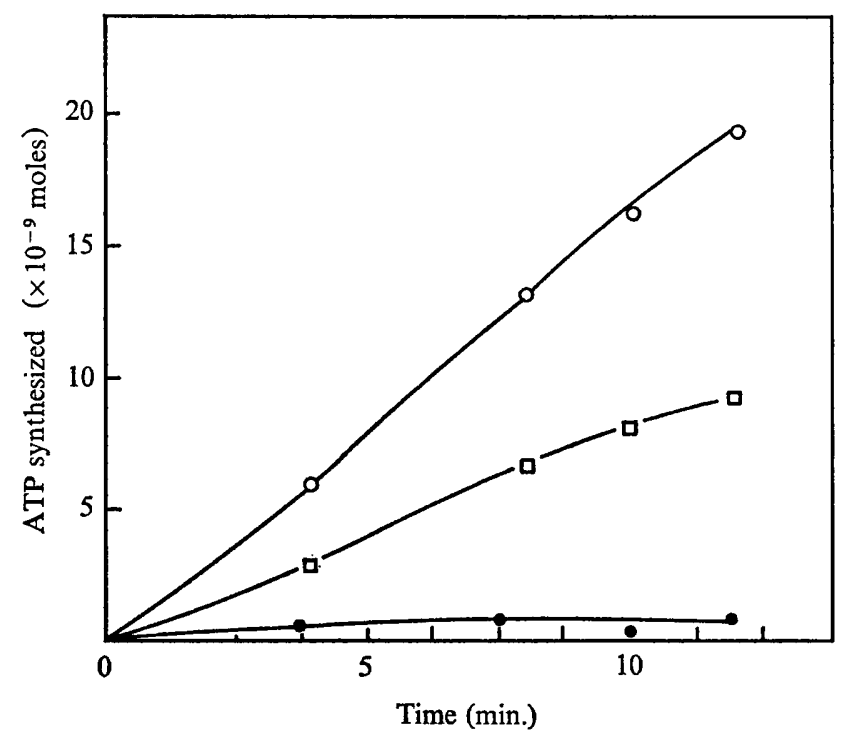

Fig. 7. The time course of synthesis of [ $\left.{ }^{32} \mathrm{P}\right] \mathrm{ATP}$ concomitant with the oxidation of reduced pyridine nucleotides by a cell-free extract of Anabaena variabilis. Reaction mixtures as described in Methods. O, NADPH; $\square, \mathrm{NADH}$;, , reduced pyridine nucleotides omitted.

tion mixture, phosphorylation was reduced by $25 \%$. Omission of reduced pyridine nucleotide, or its replacement with oxidized nucleotide, caused a marked decrease in the amount of ATP synthesized, as did the omission of ADP or its replacement with AMP. Anaerobic conditions reduced phosphorylation to less than $4 \%$ of the amount obtained by incubating under aerobic conditions (Leach \& Carr, I969).

When hexokinase and glucose were added to the standard phosphorylation mixture, the total amount of esterified $\left[{ }^{32} \mathrm{P}\right]$ phosphate remained the same, but chromatographically the radioactive material was recovered in glucose-6-phosphate although some remained as unconverted ATP.

When NADPH was replaced by the oxidized nucleotide and a substrate such as malate, which is known to lead to its reduction in extracts of Anabaena variabilis, ATP synthesis could again be demonstrated. However, the levels of phosphorylation were then substantially lower than those obtained with the reduced nucleotides (Table 3). As would be expected, succinate served as a poor source of electrons to support ATP synthesis and was independent of the addition of pyridine nucleotides. Isocitrate or malate, in the presence of $\mathrm{NADP}^{+}$, was about half as effective as the commercial reduced coenzyme. The results recorded in Table 3 are the highest and lowest 
of at least three determinations. They show quite a wide difference and this probably reflects the low rate of activity and fragility of the phosphorylating system.

The assay for ATP gave a linear response of light emitted to ATP added between the range of $2 \times 10^{-6}$ and $10^{-3} \mu$ moles of ATP. Unfortunately, the assay was found unsuitable for ATP estimations in supernatant obtained after arresting phosphorylation by adding trichloroacetic acid or perchlorate (see Methods).

The specific radioactivity of the biosynthesized ATP was I $28 \times 10^{6}$ c.p.m. $\mu$ mole, compared to the specific activity of ${ }_{1} \cdot 66 \times 10^{6} \mathrm{c} . \mathrm{p} . \mathrm{m} . \mu$ mole for the inorganic $\left[{ }^{32} \mathrm{P}\right]-$ phosphate added; the difference between these two values is probably a reflexion of the presence of a small amount of phosphate in the extract.

Table 3. Phosphorylation supported by the oxidation of organic substrates in extracts of Anabaena variabilis

$\begin{array}{lc}\begin{array}{c}\text { Incubation additions } \\ \text { Standard (see Methods) }\end{array} & \begin{array}{c}\text { ATP formed } \\ \text { (nmole/min./mg. protein) }\end{array} \\ \text { NADPH replaced by: } & 0.35 \text { to } 0.48 \\ \text { NADH } & 0.13 \text { to } 0.29 \\ \text { NADP } & 0.006 \text { to } 0.01 \\ \text { NADP+ succinate } & 0.06 \text { to } 0.08 \\ \text { NAD+ succinate } & 0.07 \text { to } 0.09 \\ \text { NADP+ malate } & 0.16 \text { to } 0.26 \\ \text { NAD+malate } & 0.09 \text { to } 0.15 \\ \text { NADP+isocitrate } & 0.16 \text { to } 0.33 \\ \text { NAD+isocitrate } & 0.09 \text { to } 0.18 \\ \text { succinate } & 0.06 \text { to } 0.11 \\ \text { malate } & 0.08 \text { to } 0.11 \\ \text { isocitrate } & 0.05 \text { to } 0.09\end{array}$

The highest and lowest results of at least three separate determinations are given.

\section{DISCUSSION}

This communication describes some stages in the dark aerobic oxidation of NADPH and NADH and an associated phosphorylation in extracts of Anabaena variabilis. The sedimentation properties of NADH oxidase described here and the effects of various inhibitors are comparable to those of another blue-green alga, Anacystis nidulans (Horton, 1968). In extracts of the five species of blue-green algae tested, NADPH was oxidized more rapidly than NADH (Leach \& Carr, 1968), and NADPH oxidation by extracts of Anab. variabilis was less sensitive to inhibitors acting prior to the terminal oxidase. In whole cells of Anac. nidulans in the dark, anaerobic conditions lead to an accumulation of NADPH and not NADH (Biggins, I969).

Biggins (1969) has observed oxidation of reduced cytochrome $c$ by extracts of Anacystis nidulans, although Horton (I968) did not observe any activity in extracts of Anac. nidulans nor Anabaena variabilis. Because of its relative insensitivity to cyanide and azide, the terminal oxidase in the respiratory electron chain of Anab. variabilis is probably of the cytochrome $o$ type, as has been observed in the colourless Cyanophyta (Webster \& Hackett, 1965; Biggins \& Dietrich, 1968) and in the photosynthetic bacterium Rhodospirillum rubrum (Horio \& Kamen, 1962). NADH oxidase is more sensitive to inhibitors of electron flow from pyridine nucleotides to quinones or cytochrome $c$ than is NADPH oxidase. This suggests that NADH and NADPH are 
oxidized by separate pathways up to the cytochrome $c$ stage. However, the fact that the rates of the oxidation of NADPH and NADH are not additive indicates that they share some stages of their dark electron transport pathway. The pyridine nucleotide: quinone oxidoreductase was readily detected with $\mathrm{NADPH}$, with either vitamin $\mathrm{K}_{1}$ or menadione as electron acceptor. Anab. variabilis does not contain vitamin $\mathrm{K}_{2}$ or ubiquinone (Carr et al. 1967), which are commonly involved in bacterial respiration. It may be that both photosynthetic electron flow and dark respiratory electron transfer in Anab. variabilis share some common components and that this may account for the photo-inhibition of respiration observed in the blue-green algae (Brown \& Webster, I953; Jones \& Myers, 1963). This explanation has been advanced by Horio \& Kamen (1962) to account for this phenomenon in Rhodospirillum rubrum. In an examination of the link between respiration and photosynthetic electron flow in Anac. nidulans, Jones \& Myers (1963) concluded that competition for electrons exists between chlorophyll $a$ and oxygen. The cytological association of the photosynthetic lamellae with reducing activity, detected by potassium tellurite and tetranitro-blue tetrazolium reduction, has been noted in Nostoc sphaericum (Bisalputra, Brown \& Weier, I969). Most of the NADPH oxidase activity in our preparations sedimented with the chlorophyll-bearing fragments, but a small portion was soluble. The latter activity, measured as a decrease in extinction at $340 \mathrm{~nm}$., may be due to NADP:ferredoxin diaphorase (E.C. I.6.99.4) which was easily separated from the photosynthetic lamellae of Anab. variabilis (Susor \& Krogmann, 1966).

Perhaps the more important question is not whether dark NADH or NADPH oxidation occurs in blue-green algae, but whether this process is linked to phosphorylation. The aerobic formation of ATP in the dark by whole cells of Anacystis nidulans was sensitive to the uncoupling agent 2,4-dinitrophenol and to the electron-flow inhibitors amytal and cyanide, but was insensitive to fluorocitrate (Batterton \& Van Baalen, 1968). These authors suggest that their observations exclude a fermentative synthesis of ATP in Anac. nidulans. Recently Biggins (1969) has shown a reduction in the cellular ATP level in Anac. nidulans in the dark when anaerobic conditions were introduced, and he has demonstrated an increase in respiratory rate when the uncoupling agents, FCCP and 2,4-dinitrophenol, were added to intact cells. In a brief communication (Leach \& Carr, 1969) the formation of ATP by extracts of Anabaena variabilis, concomitant with reduced pyridine nucleotide oxidation, was reported and in this paper these results are extended and include the aerobic formation of ATP in the presence of several substrates and oxidized nucleotides, together with a report of inhibition by the uncoupling agent FCCP. The development of a proton gradient (as occurs in micro-organisms known to effect oxidative phosphorylation) has been observed to follow the oxygenation of a dark suspension of Anab. variabilis (Scholes, Mitchell \& Moyle, 1969).

The data presented in this paper, together with the whole-cell studies cited above, show that a process of oxidative phosphorylation occurred in the obligately autotrophic Anabaena variabilis and suggests its operation in other species of blue-green algae. This phosphorylation was based on a respiratory activity which was low compared with other aerobic procaryotes (e.g. Bacillus megaterium, $Q_{\mathrm{O}_{\mathbf{z}}}$ of 120 in the presence of glucose; Weibull, 1953) and could not be increased by either exogenous substrates or by growth in the presence of oxidizable substrates (Pearce \& Carr, 1967). Possibly this low respiration rate limits the amount of ATP which could be formed. 
We suggest that this low level of phosphorylation may have a role in providing the 'energy of maintenance' (Dawes \& Ribbons, 1962) under non-photosynthetic conditions, but its contribution to a culture in the light is possibly insignificant if only because of the photoinhibition of respiration demonstrated in this organism.

The support of the Science Research Council for this work is gratefully acknowledged, and C.K.L. was in receipt of an S.R.C. Research Studentship.

We thank Miss A. Davies for help in the enzymic measurements.

\section{REFERENCES}

Avron, M. (1960). Photophosphorylation by Swiss-Chard chloroplasts. Biochimica et biophysica acta 40, 257-272.

Batterton, J. C. \& Van Baalen, C. (I968). Phosphorus deficiency and phosphate uptake in the blue-green alga Anacystis nidulans. Canadian Journal of Microbiology 14, 34I-348.

BIGGINS, J. \& DIETRICH, W. E. (I968). Respiratory mechanisms in the Flexibacteraceae. 1. Studies on the terminal oxidase system of Leucothinx mucor. Archives of Biochemistry and Biophysics 128, $40-50$.

BIGGINS, J. (1969). Respiration in blue-green algae. Journal of Bacteriology 99, 570-575.

Bisalputra, T., BRown, D. L. \& Weier, T. E. (1969). Possible respiratory sites in a blue-green alga Nostoc sphaericum as demonstrated by potassium tellurite and tetranitro-blue tetrazolium reduction. Journal of Ultrastructure Research 27, I82-197.

Block, R. J., Durrum, E. L. \& Zweig, G. (1958). A Manual of Paper Chromatography and Paper Electrophoresis. New York: Academic Press.

BRown, A. H. \& WeBSTER, G. C. (1953). The influence of light on the rate of respiration of the bluegreen alga Anabaena. American Journal of Botany 40, 753-758.

Carr, N. G. \& Pearce, J. (1966). Photohetrotrophism in blue-green algae. Biochemical Journal 99, $28 \mathrm{P}-29 \mathrm{P}$.

Carr, N. G., Exell, G., Flynn, V., Hallaway, M. \& Talukdar, S. (1967). Minor quinones of some Myxophyceae. Archives of Biochemistry and Biophysics 120, 503-507.

Dawes, E. A. \& RibBons, D. W. (1962). The endogenous metabolism of micro-organisms. Annual Review of Microbiology 16, 24I-264.

HAAs, E. (1955). TPNH cytochrome $c$ reductase in yeast. In Methods in Enzymology, vol. 2, pp. 699-703. Edited by S. P. Colowick \& N. O. Kaplan. New York: Academic Press.

HeMPFLING, W. P. \& VishniAC, W. (1965). Oxidative phosphorylation in extracts of Thiobacillus. Biochemische Zeitschrift 342, 272-287.

Hoare, D. S., HoAre, S. L. \& Moore, R. B. (1967). The photoassimilation of organic compounds by autotrophic blue-green algae. Journal of General Microbiology 49, 35I-370.

HoRIO, T. \& KAMEN, M. D. (1962). Observations on the respiratory system of Rhodospirillum rubrum. Biochemistry I, II $41-1$ I 57.

HorTon, A. A. (1968). NADH oxidase in blue-green algae. Biochemical and Biophysical Research Communications 32, 839-845.

JONES, L. W. \& MYERS, J. (1963). A common link between photosynthesis and respiration on a bluegreen alga. Nature, London $\mathbf{1 9 9}, 670-672$.

Kaplan, N. O. (1955). Pyridine nucleotide transhydrogenase. In Methods in Enzymology, vol. 2, pp. 68I-687. Edited by S. P. Colowick \& N. O. Kaplan. New York: Academic Press.

KAPLAN, N. O. (1967). Beef heart TPNH-DPN pyridine nucleotide transhydrogenase. In Methods in Enzymology, vol. 10, pp. 317-322. Edited by S. P. Colowick \& N. O. Kaplan. New York: Academic Press.

KeLLY, D. P. (1967). The incorporation of acetate by the chemoautotroph Thiobacillus neapolitanus strain c. Archiv für Mikrobiologie 58, 99-I I 6.

Kratz, W. A. \& MYers, J. (1955). Photosynthesis and respiration of three blue-green algae. Plant Physiology 30, 275-280.

LEACH, C. K. \& CARR, N. G. (I968). Reduced nicotinamide adenine dinucleotide phosphate oxidase in the autotrophic blue-green alga Anabaena variabilis. Biochemical Journal rog, 4 P. 
LEACH, C. K. \& CARR, N. G. (I969). Oxidative phosphorylation in an extract of Anabaena variabilis Biochemical Journal 112, 125-126.

Lyman, G. E. \& DeVincenzo, J. P. (1967). Determination of picogram amounts of ATP using the luciferin-luciferase enzyme system. Analytical Biochemistry 21, 435-443.

Pearce, J. \& Carr, N. G. (1967). The metabolism of acetate by the blue-green algae Anabaena variabilis and Anacystis nidulans. Journal of General Microbiology 49, 301-31 3.

PeARCE, J. \& CARR, N. G. (1969). The incorporation and metabolism of glucose by Anabaena variabilis. Journal of General Microbiology 54, 45I-462.

Pearce, J., Leach, C. K. \& CarR, N. G. (I969). The incomplete tricarboxylic acid cycle in the bluegreen alga Anabaena variabilis. Journal of General Microbiology 55, 371-378.

SCHOLES, P., Mitchell, P. \& Moyle, J. (1969). The polarity of proton translocation in some photosynthetic micro-organisms. European Journal of Biochemistry 8, 450-454.

Smith, A. J., London, J. \& STANiER, R. Y. (I967). Biochemical bases of obligate autotrophy in the blue-green algae and thiobacilli. Journal of Bacteriology 94, 972-983.

SUSOR, W. A. \& KRogMANN, D. W. (1966). Triphosphopyridine nucleotide photoreduction with cellfree preparations of Anabaena variabilis. Biochimica et biophysica acta 120, 65-72.

Trudinger, P. A. \& KELLY, D. P. (1968). Reduced nicotinamide adenine dinucleotide oxidation by Thiobacillus neapolitanus and Thiobacillus strain C. Journal of Bacteriology 95, 1962-1963.

Webster, G. C. \& Frankel, A. W. (1953). Some respiratory characteristics of the blue-green alga Anabaena. Plant Physiology 28, 63-69.

WeBSTER, D. A. \& HACKETT, D. P. (I965). Respiratory chain of colourless algae. II. Cyanophyta. Plant Physiology 4I, 599-605.

WeIBULl, C. (1953). The isolation of protoplasts from Bacillus megaterium by controlled treatment with lysozyme. Journal of Bacteriology 66, 688-695. 